\title{
Acute Lymphoblastic Leukemia
}

National Cancer Institute

\section{Source}

National Cancer Institute. Acute Lymphoblastic Leukemia. NCI Thesaurus. Code C3167.

Leukemia with an acute onset, characterized by the presence of lymphoblasts in the bone marrow and the peripheral blood. It includes the acute B lymphoblastic leukemia and acute T lymphoblastic leukemia. 